NBS

PUBLICATIONS

A UNITED STATES

DEPARTMENT OF

COMMERCE

PUBLICATION

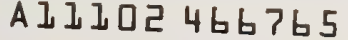

NAT'L INST OF STANDARDS \& TECH R.I.C.

A11102466765

NNBS monograph

NBS MONOGRAPH 117

Hearing Aids

U.S. DEPARTMENT OF COMMERCE National Bureau of ds

QC

100

U556

No. 117 

UNITED STATES DEPARTMENT OF COMMERCE

Maurice H. Stans, Secretary

National Bureau of Standards - Lewis M. Branscomb, Director

\title{
Hearing Aids
}

\author{
Edith L. R. Corliss
}

Institute for Basic Standards

National Bureau of Standards

Washington, D. C. 20234

National Bureau of Standards Monograph 117

Nat. Bur. Stand. (U.S.) Monogr. 117, 26 pages (Oct. 1970) CODEN: NBSMA

Issued October 1970

(Supersedes Circular 534) 
Library of Congress Catalog Card Number: 74-606242 


\section{Preface}

This publication contains information, useful to the hard of hearing, on several topics relating to hearing and hearing aids. We assume that you have already consulted a physician on the diagnosis of your hearing loss, for this is the necessary first step in correcting any faulty hearing condition. The publication may also be of interest to teachers and others wishing to explore this field.

For a number of years the National Bureau of Standards has been active in studying the properties of hearing aids - largely for such Government agencies as the Veterans' Administration. To aid in answering inquiries on the selection of such devices, a mimeographed leaflet (NBS Letter Circular 945) was issued in 1949. In 1951 Circular 516, "Selection of Hearing Aids," based on the Letter Circular was issued. In March 1953. a revision of Circular 516 was issued: the contents of the two circulars were substantially the same although some minor changes had been made, including several suggested by manufacturers of hearing aids. Circular 534 has been out of print for some time. This publication has been revised extensively; some of the new material is based upon our own research during the intervening years. 


\section{Contents}

Preface Page

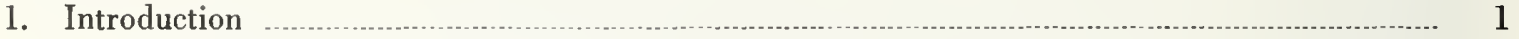

2. Some properties of sound and hearing ........ 1

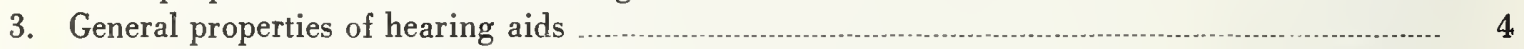

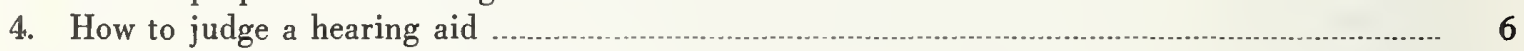

5. Guidance in choosing a hearing aid …

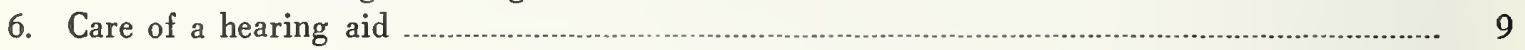

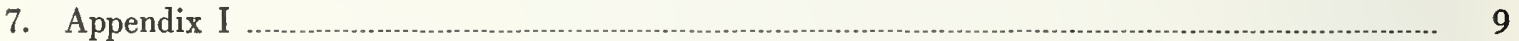

8. Appendix II. Hearing Centers ....... 10 


\title{
Hearing Aids
}

\author{
Edith L. R. Corliss
}

\begin{abstract}
This publication contains information, useful to the hard of hearing, on several topics relating to hearing and hearing aids. It is assumed that the individual has already consulted a physician on the diagnosis of his hearing loss, for this is the necessary first step in correcting any faulty hearing condition. The publication may also be of interest to teachers and others wishing to explore this field.

This publication represents an extensive revision of NBS Circular 534, Hearing Aids. It includes new material based upon research conducted at the National Bureau of Standards during the intervening years.
\end{abstract}

Key words: Audition; communications; hearing; hearing aids; selection of hearing aids; speech communication.

\section{Introduction}

Loss of hearing creates a serious problem. For most of us, the spoken word is our most important channel of communication. Even slight losses can interfere with participation in public affairs, and it does not take a very high degree of loss to hamper a person in conversation within a group.

If you have difficulty in hearing speech in a group conversation, you may find that wearing a hearing aid makes it easier for you to carry on your daily affairs. Even if you are one of the many people who have difficulty only with faint speech, you may be considered as a "marginal" hearing aid user. Your hearing loss may hinder you only in public places-at lectures, meetings, and the theater. A hearing aid would still be of decided assistance. The instrument need not be very powerful. On the other hand, because persons with a slight loss can make direct comparisons between their unaided hearing and that with an instrument, you may tend to be quite critical of the acoustical qualities of the hearing aid.

A person in need of a hearing aid has a special problem, for he himself must decide which instrument gives him the greatest benefit. Hearing aids cannot at present be fitted to individual hearing losses with the same exactitude as eyeglasses can be fitted to the refractive imperfections of the eye. We know that one reason for this lack of precision is the variety of factors causing hearing loss. A loss in hearing can occur either because the cochlear nerve has become insensitive or because the sound vibrations are conducted inefficiently from the outer to the inner ear. Each of these conditions produces a hearing loss that behaves in a distinctive manner. Loss of hearing is often due to a combination of these causes in various proportions; it is not easy to measure the proportions.

Since the earlier Circulars were published, we have had a number of years of experience with the conventional tests that also are applied to other speech communication systems such as telephones and public- address systems. These systems are designed for normal listeners. The results of conventional tests do not predict the performance of hearing aids in service to the degree we should consider definitive. Significant exceptions have been found in which a hearing aid having "defective" performance as measured by the conventional tests has proved better in service-not alone in listener preference, but in actual speech transmission-than a hearing aid that seemed to offer superior physical performance.

Some years of rueful experience reinforce our original remarks: The effectiveness of a hearing aid with known physical characteristics can be predicted only in a general way. You must pay close attention to the selection of your own hearing aid if you wish to be well fitted.

Sections $3,4,5$, and 6 describe the important properties of hearing aids, some of the criteria for judging them, and recommendations for their special care. To judge a hearing aid and to understand its limitations, it is helpful to consider the properties of sound and hearing that influence the performance of hearing aids. Section 2 contains a brief sketch of this background.

\section{Some Properties of Sound and Hearing}

The origin of the sensation of hearing is always some kind of energy. The most usual path through which hearing is stimulated starts with periodic pulsations of pressure in the air around us. These pulsations of pressure enter the outer ear and travel down the ear canal. They induce a to-and-fro motion of the drum membrane. Attached to the inner side of the drum membrane is a little chain of bones, so anchored that they take the relatively free flexible movement of the eardrum and convert it to small but very forceful motions of the fluid that fills the inner ear, or cochlea. (Cochlea is the Latin word for "snail"; the fluid chamber in the inner ear is coiled into a tight little spiral.) Within the cochlea, the fibers of the cochlear nerve end in contacts with numerous tiny structures 

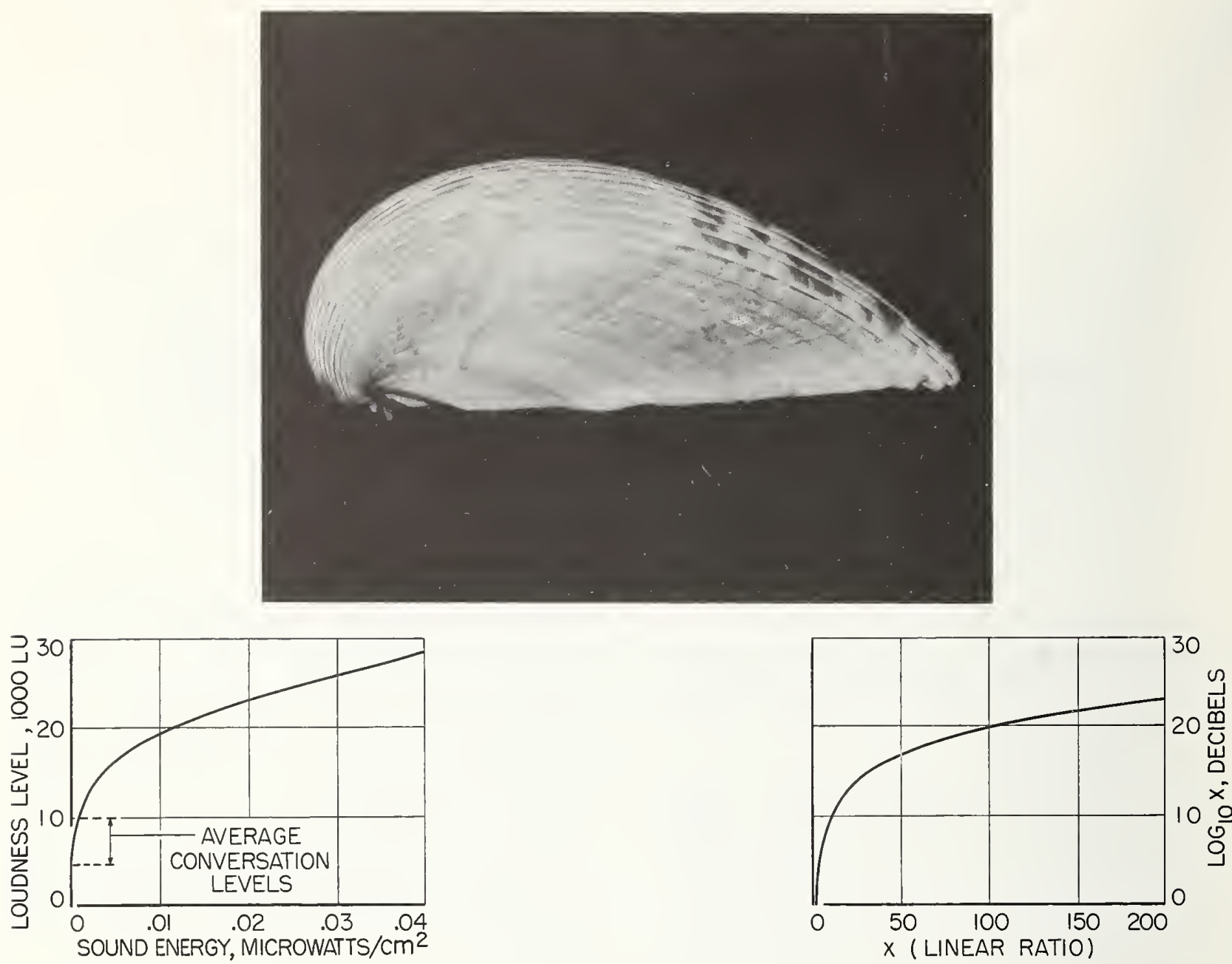

FIGURE 1. As the curve at the left shows, if the power of a sound is increased, the sensation of loudness perceived by a listener does not increase as rapidly as the increase in power.

The curve at the right shows that the logarithm of a number has much the same property. These curves show that the decibel scale, which is logarithmic, is directly related to loudness. The logarithmic scale is natural - as is shown by the profile of the sea shell (center). The animal must grow in such a way that it retains its shape, so that it continues to fit into the older part of its shell. Growth must therefore be distributed in proportion to the size of the creature already there, the shell thus forms a logarithmic curve.

called hair cells. The periodic motions of the fluid surrounding the hair cells give rise to electrical signals in the cochlear nerve. The signal ultimately reaching the brain is electrical.

Experiments have been made in which electrical signals applied to electrodes on the head produce the sensation of hearing. The conditions under which this can be done are so special that the method is not at present adaptable for hearing aids. In fact, there seems to be no way known at present to code the electrical signals externally in the same way as they are coded by the inner ear. However, these experiments do show that the ear nust translate sound pulses into electrical energy. On animals, it has been possible to measure the electrical signals sent out by the inner ear to the brain when ordinary air-borne sound is applied to the ear. In the type of hearing loss called a "nerve" or sensorineural loss, either the inner ear mechanism no longer converts the motion of the fluid efficiently into electrical power, or the cochlear nerve simply does not carry the electrical signals to the brain. An interesting and mystifying quality of nerve loss is that it sometimes acts as though a steep barrier had been placed in the path of hearing. Sounds that have enough power to override the barrier may appear almost as loud to the person having a sensorineural loss as they do to a person with normal hearing. This effect is called "Recruitment."

Another form of "sensorineural" loss is a general loss in efficiency, in which even amplified sounds are not heard with adequate precision. A person who exhibits the phenomenon of "recruitment" resembles a normal individual attempting to hear sounds in a noisy environment; he can discriminate sounds clearly if they are sufficiently intense, provided they are not so intense as to confuse his ears. Not so the person suffering from a nerve defect whose ear fails to "recruit." He has a continuing problem in resolving sounds. He may 
manage to understand speech when he is in a quiet environment, but in the presence of even a small amount of noise he may be unable to distinguish words.

If the drum membrane or the bones in the middle ear are defective, they are unable to transmit motion to the fluid in the inner ear efficiently. The resulting impairment in hearing is called "middle-ear", or "conductive", loss, because the bones in the ear do not conduct sound very well. A person having this type of loss can use two alternative types of hearing aids. He can use a hearing aid that will supply, by means of an earphone, sound pulses of increased power to his drum membrane, so that even though the middle-ear mechanism is defective, the fluid in the inner ear is set into sufficient motion. Another type of hearing aid bypasses the eardrum altogether. It moves the bones of the skull by means of a vibration device, called a "bone conductor." The motion of the skull induces motion in the fluid of the inner ear, and the sensation of hearing is produced. The bone conductor is employed where use of an earphone is precluded, and is sometimes preferred to an earphone. However, at least at present, earphones are fitted in most conductive losses because they are more efficient.

Moreover, several surgical techniques have been developed that are quite successful in reducing the degree of purely conductive hearing losses. For persons whose cochlear nerve is unimpaired, it is possible in many cases for surgery to mitigate the need for a hearing aid. That is why it is so important to obtain a good medical diagnosis whenever possible, before proceeding to acquire a hearing aid.

We are accustomed to hearing our own voices-in part, at least-through the bones of the head. The quality of the sound transmitted through the head is usually rather different from the sound transmitted through the air. As a result, recordings of our own voices sound strange to us, though each person can recognize his friends' voices from the recording. Because the sounds of their own voices reach them through the bones of the head rather than through the middle ear, persons with a "conductive" loss often have little difficulty in hearing themselves speak.

A tremendous range of energies will produce audible sound. The loudest sound to which the ear can be exposed without injury has about $1,000,000,000,000$ times the energy of the faintest sound that can just be heard. Our experience tells us at once that the ear must use a scale different from that on which these numbers have been written down. You do not judge a very loud sound to be nearly a million million times as loud as the faintest sound you can hear.

The rate at which the sensation of loudness increases with sound power is most nearly proportional, not to the total amount added, but to the size of the amount added in comparison to the sound power already pres. ent before the addition was made. Everyone agrees that three violins playing together sound louder than one. Suppose you want to double that increase in loud. ness. It is necessary to persuade more than six violinists to play in unison-you need nine, each playing at the same intensity as the original player. Unless the solo violinist is playing very softly, the problem of producing a sound several times as loud soon exceeds the resources of a symphony orchestra.

The sense of hearing follows a scale that is widespread in nature. The same scale describes such diverse things as the rising of bread dough, the spread of epidemics, and the shape of sea shells.

In figure 1 (left) the curve of loudness is plotted against equal increases in sound power. Notice that as you move to the right on the horizontal scale (increasing power), the vertical distance representing increased loudness becomes smaller for equal increases in power. To a close approximation, the increase in loudness is proportional to the ratio that the sound power added bears to the total power present. The scale that deals with increases proportional to the amount already present turns out to be a rather familiar one. Mathematicians call it a logarithmic scale. Loudness is therefore nearly proportional to the logarithm of the sound power, and in estimating loudness the ear acts on a logarithmic scale. The relation of this scale to the ordinary number scale that we see on rulers and yardsticks-the "linear" scale-can be shown by a line drawn on a graph, as in figure 1 (right). In the horizontal direction, equal distances along the scale are proportional to the ordinary number scale. In the vertical direction, equal distances along the scale are proportional to the common logarithmic scale, which expresses the numbers in terms of the number of times (whole or fractional) that the base number 10 must be multiplied by itself in order to give the ordinary number. This curve has much the same profile as the loudness-power graph. Squaring the ordinary number always doubles the logarithm, and cubing triples it.

The logarithmic relation between the loudness sensation and the sound power is the reason the sound power engineers use the decibel unit. A change of one decibel in sound level is about the difference in loud. ness between four and five violinists playing in unison. This is about the smallest difference a careful listener can detect.

Describing hearing loss in decibels gives the ratio between the least sound that a person can hear and the normal threshold. Thus, the sound that can just be heard by a person with a 20 decibel hearing loss has 100 times the power of the sound at the threshold for a person with normal hearing; correspondingly, a hearing loss of 40 decibels means that the threshold power required is 10,000 times as great as that for normal hearing. A scale of degrees of hearing loss in decibels is given in appendix 1 .

In addition to loudness, we perceive two other properties in a sound: pitch and quality. Pitch is the word used to describe how low or how shrill a sound is. The sensation of sound is produced in our ears by periodic pulsations of pressure in the air around us. Although it is affected by loudness to some minor extent, the pitch of a sound depends primarily upon the rate at which the pulsations occur. This rate, the "frequency" of the sound, is usually expressed in hertz, abbre. viated $\mathrm{Hz}$, (i.e., the number of pulsations per second). Here, again, there is a logarithmic behavior in the ear. 
Doubling the frequency changes the pitch we perceive by what we recognize as one octave. To the ear there is as great an interval between 100 and $200 \mathrm{~Hz}$ as between 2,000 and $4,000 \mathrm{~Hz}$ - one octave in each case. The frequency range of pulsations giving rise to auditory sensation extends from $30 \mathrm{~Hz}$ to about $15,000 \mathrm{~Hz}$.

From the quality of their sounds, we recognize at once the difference between a tin whistle and a flute. It turns out, upon investigation, that the sounds of a whistle, though of the same apparent pitch as those of a flute, have an admixture of pulsations of higher frequency than the base tone that determines the pitch. It is the composition of this mixture that we recognize as the quality of the sound.

There is a property related to sound that is often important in the consideration of hearing aids. That property is called "resonance." It describes the ease with which objects are set into sympathetic motion by the rhythmic pulsations of the sound. If the object has a natural mode of vibration (in which it would vibrate by itself if set off) that is of nearly the same frequency as the pulsations in the sound, it may vibrate strongly in sympathy with the sound. A system that is easily set into large motion at its natural frequency is described as "highly resonant." On the other hand, if energy is absorbed by friction, so that the sympathetic motions are limited in extent and duration, the system is said to be "damped."

Of course, the increase of response due to resonance is not a case of "something for nothing." The building up of the resonant response and its decay require a period of time. This response time changes the time scale in speech sounds, and has been found to have an important effect on their recognition. If the resonance is strong enough, it alters the duration of sounds within its range, and they become indistinguishable.

\section{General Properties of Hearing Aids}

A hearing aid is simply a personal public-address system. It has a microphone to pick up sounds, an amplifier to supply additional power, and an earphone to transmit sound to the ear. Its performance is the result of a number of factors, some of them primarily related to the ear and the brain of the user.

A person with impaired hearing has the right to demand from a hearing aid something more than bare intelligibility. Actually, the brain is capable of piecing together an entire idea from mere fragments of speech sounds. As a result, an individual whose hearing loss is not severe probably can hear and understand speech with almost any hearing aid on the market. This does not mean that he will find it effortless or pleasant. However, at best he can describe the hearing aid characteristics he desires only in a general manner, as a pleasing or "natural" quality of the transmitted sound. Or he may note that it is easier to hear through some hearing aids than it is through others.

The following discussion describes some of the characteristics of a hearing aid that are directly related to the "something more" in the relationship between the user and his hearing aid. It is only the listener himself who can determine which factor has the most weight in his particular case.

The "gain" of a hearing aid is its fundamental property. Gain represents the relative increase in power that a hearing aid produces in the sound it trans. mits. If there is a hearing loss, only a small fraction of the sound signal striking the unaided ear reaches the sensory organ in the brain. The hearing aid builds up the sound energy reaching the inner ear until it yields auditory sensation. The gain is a numerical measure of the extent to which the sound energy is built up, or "amplified."

The gain of a hearing aid is not as a rule indepen. dent of the frequency of the sound signal. However, if the instrument is to function as an aid, it must have a useful amount of gain for sound signals in the frequency range important for speech. Most speech sounds occupy the range between 150 and $6,500 \mathrm{~Hz}$. Certain parts of this range are particularly important for the reproduction of speech sounds. The distribu. tion of speech sounds, in frequency and sensation (loudness) level, is shown in figure 2. No sounds

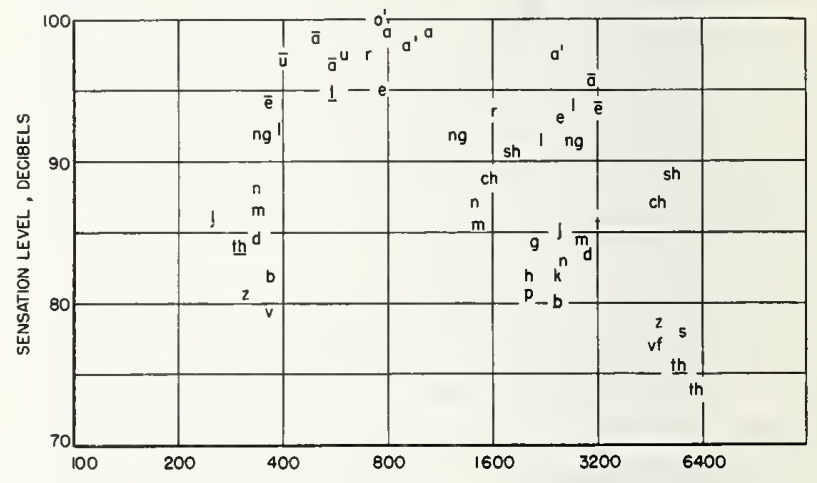

FIGURE 2. This chart shows how the sounds that make up ordinary speech are distributed both in frequency and in relative loudness.

For instance, we can see that the " $d$ " sound has important frequencies around 350 Hertz (vibrations per second), and also around, $3,000 \mathrm{~Hz}$. Unless a hearing aid reproduces these frequencies, the " $d$ " $3,000 \mathrm{~Hz}$. Unless a hearing aid reproduces these frequencies, the " $\mathrm{d}$.
sound will not be clearly heard. The height of the " $d$ " symbols in the chart shows that they are ordinarily spoken with medium loudness compared with other consonant sounds. (Chart from Speech and Hearing, by Harvey Fletcher of Bell Telephone Laboratories. Copyright 1929, by D. Van Nostrand Company, by permission of Van Nostrand Reinhold Company, New York, New York.)

necessary for understanding speech occur in the frequency region below $200 \mathrm{~Hz}$. As the figure shows, many consonant sounds will be suppressed by hearing aids that do not respond to sound in the upper part of the speech frequency range. The majority of the sounds that give speech its distinctive characteristics lie in the frequency range between 1,000 and $3,000 \mathrm{~Hz}$. The older carbon hearing aids, dependent upon resonant microphone and receiver diaphragms to increase their efficiency, were tuned to favor this frequency range. With these instruments, speech can be understood, but many individual vowels and consonants will not be clearly identified. 
The curves shown in figure 3 are acoustical gain curves measured on several representative makes of hearing aids. Some idea of how speech sounds through them can be obtained by considering what it would be like if the gain curves were traced over the phoneme [A phoneme is a discrete part of a speech sound.] chart in figure 2. The hearing loss of the user is, however, an additional factor involved in the perform. ance of a hearing aid in service.

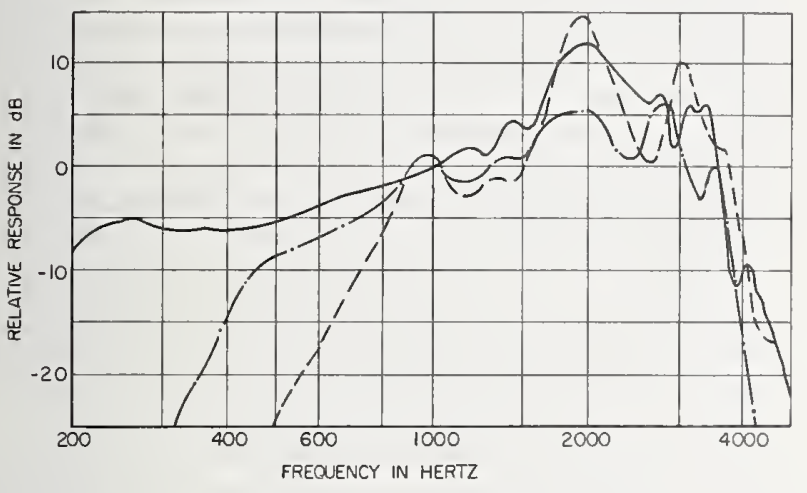

FIGURE 3. These curves show the acoustic gain, or amplification, of individual hearing aids.

The instruments were of representative makes. The solid line shows the amplification provided by a body-worn aid that provides a uniform, broadband gain. The dashed line and the dotted line show the gains for two over-the-ear instruments. Amplification of all the instruments is about the same in the middle frequency range, but instruments is about the same in the middle freq
differs considerably at higher and lower frequencies.

In general, a young or middle-aged person with the type of hearing loss caused by failure of normal conduction of sound to the inner ear can expect good results from a hearing aid. However, if the inner ear itself has become insensitive (as it frequently does in elderly persons and sometimes in young persons), it may not be possible to obtain satisfactory results from a hearing aid.

Ideally, a person using a hearing aid should hear sounds with the same loudness and tone quality as those heard by a listener with unimpaired hearing. In practice, quite a few compromises must be made. A hearing aid cannot provide hearing if the cochlear nerve is inactive; it can only amplify sounds for which the user has some cochlear nerve perception, however insensitive. In some cases of nerve impairment, sounds when heard at all are perceived to be loud. They may appear as loud to the person with nerve loss as they do to an individual with no hearing loss. But a person who has a hearing loss must wear a hearing aid to enable him to hear sounds he could not hear without the aid. When the sound is amplified to a high level, the intense sound put out by his hearing aid may be intolerably loud to the person suffering from nerve loss, and he may choose to do without the aid.

A listener recognizes large variations of the hearing aid gain with frequency as a "distortion" in the transmitted sound. If the combination of his hearing loss and the gain of the hearing aid results in sudden large changes in compensation near a particular frequency or set of frequencies, sounds occurring near those frequencies will appear to be changed in their characteristics-e.g., the tapping of heels on a floor may sound metallic or thumping. Under such circumstances, some sounds may become difficult to recognize. This type of distortion is commonly called frequency dis. tortion, because it results from inadequate frequency range or from too-sharp variations of gain with frequency.

If the range of frequencies over which the gain is uneven is quite narrow, another feature of the "resonance" effect occurs: the time scale of speech and noise sounds is altered by the fact of the resonance, and they become more nearly alike. In some hearing aids showing pronounced resonances, many listeners have no trouble recognizing speech under quiet conditions, but find it difficult to understand speech if noise is also present. A typical comment describing the property of this hearing aid is that it is "noisy," although in terms of physical measurements it may not show any unusual quantity of electrical noise in its output. Noise gener. ated by stroking the outer case of the instrument is not one of the conventional tests, but it is likely that in the presence of resonance it contributes to the listener's overall impression of noise.

Resonance creates another problem. Acoustic feedback from the earphone to the microphone of the hearing aid can occur as a result of amplification of sound leaking from the earmold to the microphone of the hearing aid. The result of this feedback is to generate a steady whistle, usually of a pitch corresponding to the frequency at which the resonance is greatest. Often, in high-powered hearing aids required by persons with a severe hearing loss, it is the generation of this whistle that limits the amplification that can be made available to the listener. Thus, another advantage of freedom from resonance is the opportunity to provide higher overall gain for persons with severe hearing loss, before feedback becomes the limitation.

Another type of distortion may have serious effects upon the sound transmitted by the hearing aid: when the sound level is too high for the power handling capacity of the hearing aid, the excess sound energy is converted by the overloaded instrument into sounds of extraneous frequencies. Overload distortion appears to a listener as a noisy blurring of loud speech sounds.

Both frequency and overload distortion in a hearing aid result from the compromises made in order to satisfy the demands for compactness and economy. Some hearing aids are built with microphones and earphones tuned to resonate in the middle of the speech frequency range. This is done to gain battery economy at the expense of uniform amplification, since uniform amplification over a wide frequency range is attained by heavily damping the natural resonances of the microphone and receiver, thus reducing their efficiency. Speech transmitted over a resonant system may sound tinny, but it will probably be intelligible under quiet conditions.

Earphones have generally less power handling capacity when their size is small. Overloading due to 
small size is most likely to occur at the lower frequencies, introducing overtones in the output sound that blur the sounds of higher frequencies that are important for the recognition of words.

An ear mold that fits properly is necessary for best performance from a hearing aid. The ear mold provides a speaking tube leading to the eardrum of the user from the earphone. If it is too loose, sound energy is lost through leakage. The sound energy escaping may be sufficient to reach the microphone of the hearing aid. When this happens, the hearing aid will "squeal" on loud sounds, and it may even squeal continuously. A hearing aid may, in fact, squeal at a frequency inaudible to the user, and he may be aware of the occurrence only because of high distortion or reduced gain.

\section{How to Judge a Hearing Aid}

In a general way, certain qualities of the sound transmitted to a user's ear by his hearing aid indicate how well his hearing is being compensated for loss. If, without reading lips, he can hear what is said but has some difficulty in recognizing which person is speaking to him, his aid provides insufficient compensation at low frequencies. If, on the other hand, he can recognize the speaker's voice but cannot tell what is being said, the aid does not offer enough compensation at high frequencies. If speech of low intensity is intelligible but loudly spoken words are blurred and noisy, the hearing aid is being used at amplifications greater than those for which it is designed. For higher amplification, it is preferable to use a more powerful instrument. An occasional person with nerve loss may notice this effect with all hearing aids. In this case, however, the distortion arises within his own ear rather than in the hearing aid.

Blurring of loud sounds may also be noticed in a hearing aid in which some part is wearing out, or when the batteries become weak. If a hearing aid that has not overloaded previously on loud sounds begins to do so and the insertion of a new battery does not remedy the condition, the hearing aid may be in need of repair.

When components with natural resonances are present, the amplification is much greater in the immediate neighborhood of the resonant frequencies. As a result, sharp sounds such as heel clicks, drum beats, or typewriter tapping, acquire a musical ringing quality. Certain speech sounds will also be affected by the resonances and will be accompanied by a ringing overtone in the transmitted sound. This may affect the intelligibility of the transmitted speech. The effect of the resonance will be particularly noticeable if there is noise present that can excite the resonance. Because the resonance colors both the speech and the noise with its own dominant characteristics, the impression produced is that the speech has faded into the noise to a greater extent than one would expect purely from listening to the noise itself. And, in fact, it becomes fairly difficult to extricate the speech from the noise. A hearing aid that affords uniform amplification over a wide frequency range will transmit sharp sounds with their unmusical and incisive character unaltered. Because noise present will not be colored by the resonance to resemble the speech, the ability to resolve the speech in the presence of noise will be preserved.

A person who has unimpaired hearing can locate the direction from which sounds are reaching him because his two ears are independent and located at a distance from one another. A similar effect can be achieved when two separate hearing aids are worn, with the sound from each microphone led to the corresponding ear. However, even at the present time, although hearing aids are quite small, most persons use a single hearing aid. The part of the hearing aid that picks up sounds (the microphone) is worn at one point on the body. With a single microphone, directions from which sounds originate cannot be recognized directly, although by moving about one might recognize from changes in the character of the sound that there is a preferred direction. Thus, the use of a single instrument increases the interference produced by extraneous noises, since the listener cannot restrict his attention to sounds from a particular direction.

Now that many persons wear hearing aids on the side of the head, as in an eyeglass, over-the-ear or even in-the-ear fitting, techniques have been worked out for reducing the problem of head shadow. The arrangement is called CROS (Contralateral Routing of Offside Signals). It is most often fitted when a person has fairly good residual hearing in one ear. A microphone is placed beside the poor ear, and the amplified signal is routed to the good ear. If the ear is good enough, an open earmold is used, so that sound reaches the good ear directly, and is combined with the amplified sound from the CROS-fitted microphone. It is also possible to supply amplified sound to the good ear from microphones located at both ears.

Tone controls are provided on some hearing aids to enable the listener to adjust the gain characteristics to suit himself. Such controls operate by reducing the amplification at lower frequencies or, sometimes, at both the low and high extremes of the frequency range. Sometimes they are suggested as a means for reducing background noise. Their use may be indicated by the following hypothetical illustration: suppose that one wants to increase the amplification but discovers that increased amplification creates an unpleasant reception because of noise in the higher frequency range; then by cutting the gain in this region by use of the tone control one may be able to increase the volume without the higher frequencies. It should be remembered, however, that reducing the gain at some frequenciesparticularly the higher-reduces the amount of information the user gets, and the higher frequencies are particularly important in speech.

A hearing aid cannot discriminate between pleasant and unpleasant sounds. Over the same range of frequencies in which desired sounds occur, there are many irritating noises that cannot be shut out. The screeching of a hinge and the scraping of a fingernail occupy the same frequency region as do the consonant sounds essential for the recognition of words. More- 
over, what may be called the "annoyance factor" of sounds is greater at higher frequencies. A person who has for years suffered a progressive loss of high-frequency hearing is therefore likely to find his first experience with a hearing aid somewhat dismaying. If it will enable him to comprehend speech, he will also rediscover the squeaks and clatter previously screened from him by his own diminished hearing. Almost any one inured to the semisilence of hearing loss may require some time to become readapted to loud sounds. Sensitive individuals may need several months or more to become accustomed to fuller hearing. Eventually most users of hearing aids come to overlook the inevitable noises for the sake of hearing speech with ease.

There are several tests that an individual can use to assist him in deciding whether he is getting the most help from his hearing aid. An inexact but very practical method for finding out how it behaves is to make an articulation test.

An articulation test is based upon the idea that the primary purpose of a hearing aid is the communication of speech. It is simply a refined method for talking to a subject and determining how much of the speech he can understand. Because understanding is involved, ordinary words common to everyone's daily life must be used. An attempt is made to choose words that represent a good sample of the sounds that make up speech. A set of such word lists, the PB or "phonetically balanced" word lists, has been developed at the PsychoAcoustic Laboratory of Harvard University.

Two of these PB word lists are given in Table 1. One list suffices for a single test, but smaller parts of a single list will not be adequate, because all the speech sounds will not be tested in their proper ratio. To avoid the effects of memory, the words should be copied on cards so that they can be presented in random order. A person who is trying out a hearing aid should get a friend to make this test with him. He should not face the reader, in order that lip reading will not affect the result. The most favorable position is for the reader to be diagonally at one side from the listener so that his face is just removed from the listener's direct line of sight. Interposition of any large obstacle between the reader and the microphone of the listener's instrument should be avoided in the test.

The presentation of the words should be done carefully. To present them naturally, they should be spoken in a sentence in a normal conversational tone. The sentence must be chosen so that the test words cannot be inferred from the rest of the sentence. A carrier sentence commonly used is "You will say *** now." This sentence has the advantage that the "a" sound in "say" is a high-level sound and can be used by the speaker for checking on his voice level. The sentence should be spoken at ordinary conversational level.

It is unlikely that the person making the test will get 100 percent of the words correctly. Even under ideal communication conditions (with two persons in the same quiet room, but not facing each other) the random word articulation scores are usually 95 percent. Apparently, individuals with normal hearing actually judge the remaining 5 percent of the words in
TABLE 1. Word lists for articulation test8

\begin{tabular}{l|l||l|l}
\hline \multicolumn{2}{c}{ PB-50 List 1} & \multicolumn{2}{c}{ PB-50 List 2} \\
\hline 1. ache & 26. muck & 1. bath & 26. neat \\
2. air & 27. neck & 2. beast & 27. new \\
3. bald & 28. nest & 3. bee & 28. oils \\
4. barb & 29. oak & 4. blonde & 29. or \\
5. bead & 30. path & 5. budge & 30. peck \\
6. cape & 31. please & 6. bus & 31. pert \\
7. cast & 32. pulse & 7. bush & 32. pinch \\
8. check & 33. rate & 8. cloak & 33. pod \\
9. class & 34. rouse & 9. course & 34. race \\
10. crave & 35. shout & 10. court & 35. rack \\
11. crime & 36. sit & 11. dodge & 36. rave \\
12. deck & 37. size & 12. dupe & 37. raw \\
13. dig & 38. sob & 13. earn & 38. rut \\
14. dill & 39. sped & 14. eel & 39. sage \\
15. drop & 40. stag & 15. fin & 40. scab \\
16. fame & 41. take & 16. float & 41. shed \\
17. far & 42. thrash & 17. frown & 42. shin \\
18. fig & 43. toil & 18. hatch & 43. sketch \\
19. flush & 44. trip & 19. heed & 44. slap \\
20. gnaw & 45. turf & 20. hiss & 45. sour \\
21. hurl & 46. vow & 21. hot & 46. starve \\
22. jam & 47. wedge & 22. how & 47. strap \\
23. law & 48. wharf & 23. kite & 48. test \\
24. leave & 49. who & 24. merge & 49. tick \\
25. lush & 50. why & 25. move & 50. touch \\
& & &
\end{tabular}

ordinary conversation by familiarity, context, or lip reading.

By noticing the particular speech sounds that are missed by the listener in writing down the word list, and comparing them with the chart in figure 2 , it is possible to get some idea of the particular way in which the hearing aid fails to compensate for hearing loss.

Perhaps the simplest way for determining whether a hearing aid has a resonance is to listen to footsteps or a typewriter and notice whether a particular note seems to be favored. If there is access to a piano, the resonance can be found by having someone play through the keyboard range several times with a uniform touch. If the hearing aid gain is uneven, certain notes will sound markedly louder or softer than the rest. Experimentation shows that peaks can be detected in this way if they are greater than 20 decibels in magnitude.

In general, the presence of competing noise is a critical test of the performance of hearing aids. Problems with overload and resonance become strikingly evident when noise is present to be mixed with the speech. You should try your prospective hearing aid under noisy conditions as well as in the quiet.

Occasionally you may find a hearing aid that picks up hum from power systems and fluorescent lights. Even though you may have no fluorescent lights in your house, they often are used in restaurants and stores. This form of pickup is strongly directional; if you suspect it is giving trouble, you can try turning the hearing aid. Usually, with hum pickup, you can find a position in which the hum is at a minimum. Most modern hearing aids are designed to avoid this trouble.

In many hearing aids, especially those designed for 
higher amplification, the ability to pick up a stray magnetic field is used as a virtue; a special pickup coil is connected so that it may be switched into the ampli. fier as a substitute for the microphone, and it may be used in place of the microphone to pick up the signal from a telephone receiver. Since it works only on the magnetic field of the receiver, it cuts down markedly on the room noise reaching the hearing aid. Many high-gain hearing aids contain this feature, and you may want to try it.

\section{Guidance in Choosing a Hearing Aid}

The first step in overcoming loss of hearing is to determine whether the condition responsible for the loss can be remedied or at least checked in its progress by medical treatment. Some causes of conductive loss can be remedied by surgery. The nature of the hearing loss should be found in order to know whether the loss can be compensated by a hearing aid. For the answers to these questions a physician, preferably an ear specialist, should be consulted.

If medical examination indicates that a hearing aid will be helpful. the next problem is the selection of the instrument. Numerous makes are on the market, offering a wide variety of choices. Most manufacturers offer two or more models. Some dealers undertake to provide assistance in the selection of a particular model (from among their own instruments) by methods more or less similar to those outlined in the previous section.

A person shopping for a hearing aid may find it helpful to take with him a person with normal hearing so that, as he tries out different instruments, he may listen to words spoken by the same person. The prospective user should if possible try out one or more hearing aids in his own ordinary surroundings. Some companies provide a trial plan, occasionally charging a nominal rental that may be applied to the price of the instrument if it is purchased.

Hearing aids are designed to be worn as inconspicuously as possible. For people with mild and moderate losses, instruments may be made so small that they can be worn on the head in some way. They are sometimes concealed in the frames of spectacles, with only a plastic tube leading from the earphone to the earmold. (This may make it inconvenient to wipe the lenses because it becomes necessary to detach the hearing aid from the ear.) Over-the-ear hearing aids are very commonly used, and have the advantage of being inconspicuous, without being bound to the eyeglasses. For mild losses, a small hearing aid can be built directly into an earmold.

These head-worn aids have certain acoustical advantages. There is no clothing noise produced. The instrument is not muffled by clothing, and the listener can rotate his head to receive the best sound, just as he. could if he were not wearing a hearing aid. Some compromises in sound quality must be made because of the small size of these types of hearing aids. The use of plastic tubing to conduct sound to the ear produces an irregular frequency response characteristic. However, the good points of head-worn hearing aids make them worth consideration by many people.

If the hearing loss is severe, a body-worn hearing aid is necessary. The better sound quality that is possible because of the external earphone and larger size often makes them desirable for other degrees of loss, also. Elderly persons find them easier to operate than a head-worn aid. When comparing a body-type aid with a head type, the body instrument should be placed in the pocket or under the clothing, just as it will be in actual use.

Some persons are made self-conscious by the visibility of their hearing aids. However, some users report that the hearing aid is helpful even when it is not turned on. Conscientious speakers tend to be more careful of their diction when reminded that a communication problem exists. In any case, when a person is observed to take part in a conversation with ease, few persons continue to be aware of how the process is achieved, just as many of us are not sure of which of our friends wear eye glasses.

If you wish to obtain the best possible hearing, make your selection on the basis of performance and not merely on cosmetic appeal. However, do consider that the hearing aid is worn continuously for a long time, and consider how comfortable it feels.

A convenient pocket-sized pamphlet "Choosing a Hearing Aid" has been published by the Children's Bureau, U. S. Department of Health, Education and Welfare. It is listed as Children's Bureau Folder No. 55-1965 and can be purchased from the Superintendent of Documents, U. S. Government Printing Office, Washington, D. C. 20402. The price is 15 cents (stamps not accepted). You may find it useful to carry with you as a pocket memorandum.

After the hearing aid is selected, there is often the problem of indoctrination and of learning to make the best use of the hearing aid. This problem may be severe if the user has waited so long before purchasing a hearing aid that he has begun to forget what voices and noises really sound like and how noisy the world is. Also he may have waited until he is too old to learn readily how to adapt himself to a new device. The quality of speech heard through a hearing aid may differ from that to which he has become accustomed. The transition may be considerably helped by wearing the instrument for only an hour or two each day at first and by some systematic "auditory training" or practice in listening.

To assist the hard of hearing in some of these problems a number of "hearing centers" have been established throughout the country. Most of them are nonprofit civic enterprises under the auspices of local universities or hospitals; frequently a nominal fee for their services is charged to those who can pay it.

These centers provide a variety of services, including in many cases advice on the selection of hearing aids. Practically all of them give hearing tests. Many offer otological examination by an ear specialist, and the majority provide other forms of assistance such as auditory training, lip reading, speech training, and vocational counseling. 
The hearing centers that offer demonstrations of hearing aids give prospective users an opportunity to try the types they have. Manufacturers are invited to submit instruments representing their current models, and although not all manufacturers are represented a wide variety of makes is usually available. This program has been assisted by a number of manufacturers and dealers who have supplied hearing aids voluntarily to the hearing centers. Partly because hearing centers cannot provide samples of all makes of hearing aids, they cannot be sure of guiding a person to the hearing aid best suited for him, but can give him a general idea of the compensation provided by hearing aids of various types. The centers do not sell hearing aids; an individual goes to commercial sources of supply to purchase his own instrument.

The Professional Services Board of the American Boards of Examiners in Speech Pathology and Audio. logy registers clinical facilities which meet minimum professional standards in this field. A list of registered clinical facilities, as well as the criteria used in their evaluation, may be obtained by writing to the American Boards of Examiners in Speech Pathology and Audiology, 9030 Old Georgetown Road, Washington, D. C. 20014.

For convenience, a partial list of clinical services is contained in appendix II.

\section{Care of a Hearing Aid}

A hearing aid is somewhat different from other devices that a person uses in his daily life, and a small amount of special care in handling it may pay substantial dividends in increased usefulness and better performance. The sensitive element in some amplifiers is injured by exposure to high temperatures, and will be ruined permanently by temperatures above $120^{\circ} \mathrm{F}$. Such temperatures may be produced locally if the aid is left lying in the sun, in a closed parked car, or too near a radiator. In several instruments these components are made of special high-temperature materials. However, batteries also deteriorate more rapidly at elevated temperatures. For such reasons, it is well to protect aids from extremes of temperature.

The electrolyte in the batteries is either a moderately strong acid or a strong alkali and may cause damage if the battery cases leak. This is likely to happen when the battery is run down. For this reason, it is advisable to separate the battery from the instrument when it is not being worlı, especially if the battery is mounted in the amplifier case. Since the battery case is consumed in the chemical process that produces electricity in the battery, usually it is not practical to recharge the batteries. Although this is suggested sometimes as an economy measure, the probability of leakage or bursting is greatly increased because the case material is not renewed by recharging. There are some cells on the market designed for recharging. They are true storage batteries and are usually somewhat more expensive on initial purchase than dry-cell batteries.
Rechargeable nickel-cadmium cells are available in sizes that fit ordinary dry-cell mountings. Their life per discharge is approximately one-third that of a drycell but they are rechargeable for a large number of cycles.

The Bureau acknowledged "the assistance and sug. gestions provided by the National Research Council's Committee on Hearing, the Volta Bureau, the American Hearing Society, the Audiology and Speech Correction Center at Walter Reed Hospital, and many interested individuals" in the Preface to Circular 516. Again, we are indebted to our many friends, among whom we should like to mention: the American Speech and Hearing Association, the Alexander Graham Bell Association for the Deaf, the National Association of Hearing and Speech Agencies (formerly the American Hearing Society), and the Committee on Hearing and Bioacoustics of the National Academy of Sciences.

\section{Appendix I}

The committee on Conservation of nearing of the American Academy of Ophthalmology and Otolaryngol. ogy recommends the division of the handicap of hearing into classes or grades, according to the accompanying table. The over-all handicap of impaired hearing is best estimated in terms of ability to hear everyday speech well enough to understand it, but for statistical purposes the more precise measurements of pure-tone audiometry are preferable.

Each class shown in table 2 is defined in terms of the average hearing threshold level for three audio. metric frequencies that are important for the understanding of speech.

\section{Editor's Note:}

The symbol ISO stands for the threshold standards set by the International Standards Organization. These correspond to somewhat more acute hearing as a norm than do the standards of normal threshold of hearing previously current in the United States. For audiometers standardized against the older U.S. standards (often abbreviated ASA for the American Standards Association), the corresponding hearing loss levels are approximately $10 \mathrm{~dB}$ less at frequencies of 500,1000 . and $2000 \mathrm{~Hz}$. An example of this situation is as follows: A person whose hearing threshold averaged for the frequencies 500,1000 , and $2000 \mathrm{~Hz}$ is $50 \mathrm{db}$ (ASA) would have the same degree of hearing loss as a person whose hearing loss was $60 \mathrm{~dB}$ (ISO). To translate the categories listed in this table for the audiograms obtained with instruments adjusted to the older ASA standards, subtract $10 \mathrm{~dB}$ from each of the category boundaries. (The standards have changed; the diagnosis has not.) Ultimately, it is expected that audiometers will be referred to the ISO norms, but at present the changeover is not near completion. 
TABLE 2. Classes of hearing handicap

(ISO-1964)

\begin{tabular}{|c|c|c|c|c|c|}
\hline \multirow[t]{2}{*}{$d B$} & \multirow[t]{2}{*}{ Class } & \multirow[t]{2}{*}{$\begin{array}{l}\text { Degree of } \\
\text { Handicap }\end{array}$} & \multicolumn{2}{|c|}{$\begin{array}{l}\text { Average Hearing } \\
\text { Threshold Level for } \\
500,1000 \text { and } 2000 \mathrm{~Hz} \\
\text { in the Better Ear* }\end{array}$} & \multirow[t]{2}{*}{$\begin{array}{l}\text { Ability to } \\
\text { Understand Speech }\end{array}$} \\
\hline & & & More Than & $\begin{array}{l}\text { Not } \\
\text { More Than }\end{array}$ & \\
\hline \multirow{2}{*}{25} & A & Not significant & & $\begin{array}{l}25 \mathrm{~dB} \\
\text { (ISO) }\end{array}$ & $\begin{array}{l}\text { No significant difficulty } \\
\text { with faint speech. }\end{array}$ \\
\hline & B & Slight Handicap & $\begin{array}{l}25 \mathrm{~dB} \\
(\mathrm{ISO})\end{array}$ & $40 \mathrm{~dB}$ & $\begin{array}{l}\text { Difficulty only with } \\
\text { faint speech. }\end{array}$ \\
\hline 40 & $\mathrm{C}$ & Mild Handicap & $40 \mathrm{~dB}$ & $55 \mathrm{~dB}$ & $\begin{array}{l}\text { Frequent difficulty with } \\
\text { normal speech. }\end{array}$ \\
\hline 55 & $\mathrm{D}$ & Marked Handicap & $55 \mathrm{~dB}$ & $70 \mathrm{~dB}$ & $\begin{array}{l}\text { Frequent difficulty with } \\
\text { loud speech. }\end{array}$ \\
\hline 70 & $\mathrm{E}$ & Severe Handicap & $70 \mathrm{~dB}$ & $90 \mathrm{~dB}$ & $\begin{array}{l}\text { Can understand only } \\
\text { shouted or amplified speech. }\end{array}$ \\
\hline 90 & $\mathrm{~F}$ & Extreme Handicap & $90 \mathrm{~dB}$ & & $\begin{array}{l}\text { Usually cannot understand } \\
\text { even amplified speech. }\end{array}$ \\
\hline
\end{tabular}

*Whenever the average for the poorer ear is $25 \mathrm{~dB}$ or more greater than that of the better ear in this frequency range, $5 \mathrm{~dB}$ are added to the average for the better ear. This adjusted average determines the degree and class of handicap. For example, if a person's average hearing threshold level for 500,1000 , and $2000 \mathrm{~Hz}$ is $37 \mathrm{~dB}$ in one ear and $62 \mathrm{~dB}$ or more in the other his adjusted average hearing threshold level is $42 \mathrm{~dB}$ and his handicap is Class $\mathrm{C}$ instead of Class $\mathrm{B}$.

\section{Appendix II. Hearing Centers}

The following list of hearing centers has been compiled from a current list supplied by the National Association of Hearing and Speech Agencies, supplemented by our own correspondence. This list is of necessity incomplete, but it is included as an aid to the reader.

The American Speech and Hearing Association publishes a list of more than 900 sources of speech and hearing clinical services in a "Guide to Clinical Ser. vices in Speech Pathology and Audiology." A copy of this Guide may be obtained by writing to the American Speech and Hearing Association, 9030 Old Georgetown Road, Washington, D. C. 20014. Other lists of facilities may be obtained from the Volta Bureau, 1537 35th Street, N.W., Washington, D. C. 20007, The National Society for Crippled Children and Adults, 2023 West Ogden Avenue, Chicago, Illinois 60612, and the National Association of Hearing and Speech Agencies, 919 18th Street, N.W., Washington, D. C. 20006.

The Veterans Administration maintains, at present, a testing program for use in purchase of hearing aids. The tests cover a relatively limited range of instruments. However, if an instrument you are considering for selection happens to be included in the VA program, you may be able to make use of its annual report. The 1970 issue is priced $\$ 2.50$, available from the Superintendent of Documents, U.S. Government Printing Office. It is titled "Hearing Aid Performance Measurement Data and Hearing Aid Selection Procedures, Contract Year 1970."

\section{ALABAMA}

Speech and Hearing Clinic Auburn University

Auburn, Alabama 36830

Medical College of Alabama 1919 7th Avenue, S.

Birmingham, Alabama 35233

Speech and Hearing Department Huntsville Rehabilitation Center 316 Longwood Drive Huntsville, Alabama 35801

Speech and Audiology Department Mobile Rehabilitation Center 1874 Pleasant Avenue

Mobile, Alabama 36607

Speech and Hearing Clinic Alabama College

306 Oak Street

Montevallo, Alabama 35115

Central Alabama Rehabilitation Center Speech and Hearing Department 2125 E. South Blvd.

Montgomery, Alabama 36111

Northeast Alabama Rehabilitation Center E. Avalon Avenue

Muscle Shoals City, Alabama 35662

Alabama Institute for Deaf \& Blind

Comprehensive Center

Dowling Hospital

205 East South Street

P. O. Box 268

Talladega, Alabama 35160 
Speech and Hearing Center

P. O. Box 1965

University of Alabama

University, Alabama 35486

\section{ARIZONA}

Arizona State University

Tempe, Arizona 85281

Department of Speech

University of Arizona

College of Fine Arts

Tucson, Arizona 85721

\section{ARKANSAS}

Arkansas State Teachers College

Conway, Arkansas 72032

\section{CALIFORNIA}

Kern County Hospital

1830 Flower Street

Bakersfield, California 93305

Chico State College

lst and Normal

Chico, California 95926

Rancho Los Amigos Hospital

Downey, California 90240

Glendale Hearing Society

1041 North Glendale Avenue

Glendale, California

Inglewood Hearing Society

12419 Menlo

Hawthorne, California 90250

Audiology and Speech Clinic White Memorial Medical Center 304 N. Boyle Avenue

Los Angeles, California 90033

Beverly-Hollywood Hearing Society 3770 Tracy Street

Los Angeles, California 90027

California State College at Los Angeles 5151 State College Drive

Los Angeles, California 90032

Children's Hospital of Los Angeles 4614 Sunset Blvd.

Los Angeles, California 90027

Department of Eye, Ear, Nose, Throat and Dentistry 1322 North Vermont Avenue Los Angeles, California 90027

HEAR Foundation of Los Angeles 4507 York Blvd.

Los Angeles, California 90041

John Tracy Clinic

806 W. Adams Blvd.

Los Angeles, California 90007

Los Angelss Co. General Hospital 1200 N. State Street

Los Angeles, California 90033

Los Angeles Eye and Ear Hospital 500 S. Lucas Avenue Los Angeles, California 90017
Los Angeles Society for Hard of Hearing, Inc.

1660 Arlington Avenue

Los Angeles, California 90019

Speech and Hearing Clinic

University of Southern California

Kerckhoff Hall

734 W. Adams Blvd.

Los Angeles, California 90007

University of Southern California

1200 N. State Street

Los Angeles, California 90033

Children's Hospital Medical Center of Northern ralifornia 5 lst \& Grove Streets

Oakland, California 94609

Stanford University

School of Medicine

300 Pasteur Drive

Palo Alto, California 94304

Mt. Diablo Therapy Center

100 Golf Club Road

Pleasant Hill, California 94523

Pomona Valley Hearing Society, Inc. 1139 N. Garey Avenue

Pomona, California 91767

Southern California Hearing Council 21322 Hipass Drive

Pomona, California 91766

University of Redlands

Redlands, California 92373

Sacramento Hearing Society

5275 - F Street

Sacramento, California 95819

HEAR Foundation of San Bernardino

3rd \& E Streets

San Bernardino, California 92401

San Diego Speech and Hearing Center 8001 Frost Street

San Diego, California 92123

San Francisco Hearing \& Speech Center 2340 Clay Street San Francisco, California 94115

San Francisco Hearing Society, Inc. 1428 Bush Street

San Francisco, California 94109

Communication Disorders Clinic

San Francisco State College

1600 Holloway Avenue Ed 101

San Francisco, California 94132

University of California Medical Center 3rd \& Parnassus Streets

San Francisco, California 94122

San Jose Hearing Society

1403 Kiner Street

San Jose, California 95125

San Jose State College

San Jose, California 95114

Orange County Hearing Society

1209 North Broadway

Santa Ana, California 92701 
HEAR Foundation of Tri-Counties 1235 Veronica Spr. Rd.

Santa Barbara, California 93103

University of California at Santa Barbara Santa Barbara, California 930]6

Santa Cruz Hearing Society

Box 304

Santa Cruz, California 95060

Speech \& Hearing Clinic

Stanford Medical Center

300 Pasteur Drive

Stanford, California 94305

University of Pacific

3601 Pacific

Stockton, California 95204

HEAR Foundation of Tulare County

115 W. Main

Visalia, California 93277

Whittier College

525 Olive

Whittier, California 90605

\section{COLORADO}

University of Colorado

930 Broadway

Boulder, Colorado 80302

Colorado Hearing Society, Inc. 1375 Delaware

Denver, Colorado 80204

University of Colorado Medical School 4200 E. 9th Avenue

Denver, Colorado 80220

University of Denver

Hearing Clinic

2065 South York

Denver, Colorado 80210

Colorado State College

Greeley, Colorado 80631

Speech and Hearing Services Curative Work Shop Society 10th and West Streets

Pueblo, Colorado 81003

\section{CONNECTICUT}

Speech and Hearing Clinic

85 Park Avenue

Bridgeport, Connecticut 06604

Greenwich Hospital

Greenwich, Connecticut 06830

Hartford Hospital

Retreat Avenue

Hartford, Connecticut 06103

Hearing and Speech Center Yale-New Haven Hospital 789 Howard Avenue

New Haven, Connecticut 06504

New Haven Hearing \& Speech Center 100 York Street

New Haven, Connecticut 06516
New Haven Hearing League

378 Congress Avenue

New Haven, Connecticut 06519

Newington Hospital for Crippled Children 181 Cedar Street

Newington, Connecticut 06111

University of Connecticut

Storrs, Connecticut 06268

Hartford Hearing League, Inc.

10 North Main Street

West Hartford, Connecticut 06107

DELAWARE

Audiology \& Speech Center

Delaware Division

Wilmington Medical Center

Wilmington, Delaware 19899

League for Hearing Impaired Children Box 644

Wilmington, Delaware 19899

\section{DISTRICT OF COLUMBIA}

Audiology and Speech Center Walter Reed Army Hospital Washington, D. C. 20012

Audiology Clinic

Gales Health Center

65 Massachusetts Avenue, N.W.

Washington, D. C. 20001

The Catholic University of America 7th \& Michigan Avenue, N.E. Washington, D. C. 20017

Children's Hospital of D. C. 2220 11th Street, N.W.

Washington, D. C. 20001

D. C. General Hospital

19th St. \& Mass. Ave.

Washington, D.C. 20003

Georgetown University Medical Center 3800 Reservoir Road

Washington, D. C. 20007

Hearing and Speech Center

Gallaudet College

Florida Ave. at 7th NE

Washington, D. C. 20002

Speech-Hearing Language Center

Crippled Children's Service

D. C. General Hospital

2215 Independence Avenue, S.E.

Washington, D. C. 20003

Speech and Hearing Center

Washington Hospital Center

110 Irving Street, N.W.

Washington, D. C. 20010

Washington Hearing Society

1934. Calvert St., NW

Washington, D. C. 20009

FLORIDA

University of Miami

Coral Gables, Florida 33134 
Hearing Society Volusia County Box 1085

Daytona Beach, Florida 32019

Speech and Hearing Clinic

University of Florida

Gainesville, Florida 32601

Univ. of Florida Medical School Department of Communicative Disorders Gainesville, Florida 32603

Speech and Hearing Center, Inc. 625 Ocean Street Jacksonville, Florida 32201

Hearing \& Speech Center of Florida, Inc. 1540 W. Flagler Street Miami, Florida 33135

Univ, of Miami, School of Medicine 1700 N.W. 10th Ave. Miami, Florida ?3152

Sarasota Hearing Society 1224 So. Tamiami Trail Sarasota, Florida 33579

Florida School for the Deaf \& the Blind P. O. Box 1221

St. Augustine, Florida 32084

Jr. Service League, Speech \& Hearing Clinic P. O. Box 244

St. Augustine, Florida 32084

Florida State University

Tallahassee, Florida 32306

Curtis Hixon Rehabilitation Center

Tampa General Hospital, Davis Is.

Tampa, Florida 33606

Tampa Oral School for the Deaf, Inc. P. O. Box 10706

Tampa, Florida 33609

\section{GEORGIA}

University of Georgia Athens, Georgia 30601

Atlanta Speech School 3160 Northside Parkway, N.W. Atlanta, Georgia 30327

Davison School of Speech Correction 1780 N. Decatur Road, NE Atlanta, Georgia 30307

Easter Seal Rehab. Center 1362 W. Peachtree, N.W. Atlanta, Georgia 30309

Emory University Speech School 2020 Peachtree Road, N.W. Atlanta, Georgia 30309

Emory University Clinic Section of Audiology 1365 Clifton Road, N.E. Atlanta, Georgia 30322

Augusta Speech and Hearing Center University Hospital Augusta, Georgia 30902
Glynn Speech and Hearing Center

1803 Gloucester Street

Brunswick, Georgia 31520

Central Georgia Speech \& Hearing Center 514 First Street

Macon, Georgia 31201

Moultrie Speech \& Hearing Center 901 Fifth Street, S.W.

Moultrie, Georgia 31768

Savannalı Speech and Hearing Clinic 1206 East 66th Street

Savannah, Georgia 31404

Valdosta Speech and Hearing Clinic 1115 North Ashley

Valdosta, Georgia 31601

IDAHO

Hearing and Speech Dept

Idaho Society for Crippled Children 128 South 5 th

Boise, Idaho 83702

Speech \& Hearing Clinic

Idaho State University

Pocatello, Idaho 83201

\section{ILLINOIS}

Southern Illinois Univ.

WHAM Education Bldg.

Carbondale, Illinois 62901

Speech and Hearing Clinic

Southern Illinois Univ.

Carbondale, Illinois 62901

Warren G. Murray Children Center Centralia, Illinois 62801

Hearing Clinic

University of Illinois

322 Illini Hall

Champaign, Illinois 61820

Audiology Service

Children's Memorial Hospital

2300 Children's Plaza

Chicago, Illinois 60614

Auditory Research Laboratory

Northwestern University

303 East Chicago Avenue

Chicago, Illinois 60611

Chicago Hearing Society

$30 \mathrm{~W}$. Washington St.

Chicago, Illinois 60602

Michael Reese Hospital Henner Speech \& Hearing Center 2929 S. Ellis Ave.

Chicago, Illinois 60616

Section of Otolaryngology

Department of Surgery

University of Chicago

Chicago, Illinois 60637

Speech and Hearing Clinic Presbyterian St. Luke's Hospital $1753 \mathrm{~W}$. Congress Parkway Chicago, Illinois 60612 
Speech \& Hearing Clinic

Schwab Rehabilitation Center

1409 So. California

Chicago, Illinois 60608

Speech \& Hearing Clinic St. Josephs Hospital

2900 N. Lakeshore Dr.

Chicago, Illinois 60657

Speech and Hearing Rehabilitation Clinic

Univ of Illinois

904 W. Adams St.

Chicago, Illinois 60607

Speech and Hearing Station

Communicative Processes Study Center

University of Illinois at the Medical Center

1855 West Taylor Street

Chicago, Illinois 60612

Speech and Hearing Clinic

Northern Illinois Univ.

DeKalb, Illinois 60115

Elmhurst College

190 Prospect Ave.

Elmhurst, Illinois 60126

Eastern Illinois Univ.

Evanston, Illinois 61920

Northwestern University Hearing Clinics Speech Annex

Evanston, Illinois 60201

MacMurray College

Jacksonville, Illinois 62650

College of St. Francis

500 Wilcox St.

Joliet, Illinois 60435

Lincoln State School

Hearing and Speech Dept.

861 So. State St.

Lincoln, Illinois 62656

Speech \& Hearing Clinic

Fairchild Hall 205

Illinois State Univ.

Normal, Illinois 61761

Speech and Hearing Clinic

Bradley Univ.

815 Glenwood

Peoria, Illin ois 61606

Rockford College

Speech Department

5050 E. State

Rockford, Illinois 61101

The Winnetka Inst. for Hearing and Speech 614 Lincoln Avenue

Winnetka, Illinois 60093

\section{INDIANA}

Clinical Audiology Lab.

Speech and Hearing Center

Indiana Univ.

Bloomington, Indiana 47401

Gary Hearing Society

225 Joliet Street

Dyer, Indiana 46311
Tri-State Hearing \& Speech Assn.

3701 Bellemeade Ave.

Evansville, Indiana 47715

Community Coordinating Center for Rehabilitation \& Health Service

227 East Washington St.

Fort Wayne, Indiana 46802

Fort Wayne Hearing Society 1027 E. Wayne St.

Fort Wayne, Indiana 46802

Trade Winds Rehab. Center 5901 W. 7th Ave.

Gary, Indiana 46406

Audiology \& Speech Clinic Indiana University Medical Center

Indianapolis, Indiana 46202

Indiana School for the Deaf 1200 E. 42nd Street Indianapolis, Indiana 46205

Indianapolis Speech \& Hearing Center 615 North Alabama St.

Indianapolis, Indiana 46204

Speech \& Hearing Clinic

Purdue Univ.

LaFayette, Indiana 47907

Hearing \& Speech Center of St. Joseph Co. 208 North Ironwood

Mishawaka, Indiana 46544

Speech \& Hearing Clinic

Ball State Univ.

Muncie, Indiana 47306

Indiana State Univ.

Terre Haute, Indiana 47809

Purdue Univ.

West Lafayette, Indiana 47907

\section{IOWA}

Cedar Rapids Hearing Society

615 - 30th Street, S.E.

Cedar Rapids, Iowa 52403

State College of Iowa

Cedar Falls, Iowa 50613

Iowa School for the Deaf Council Bluffs, Iowa 51501

Des Moines Hearing \& Speech Center 700 Sixth Ave.

Des Moines, Iowa 50309

See-Hear Organization, Inc. P. O. Box 505

Dubuque, Iowa 52001

Grinnell College

Park Street

Grinnell, Iowa 50112

Division of Speech and Hearing Department of Otolaryngology and Maxillofacial Surgery University Hospitals Iowa City, Iowa 52240 
State Univ, of Iowa

308 Melrose Avenue

Iowa City, Iowa 52240

University of Iowa Speech and Hearing Clinic Wendell Johnson Speech and Hearing Center Iowa City, Iowa 52240

Speech \& Audiology Department Siouxland Rehabilitation Center 40629 th Street Sioux City, Iowa 51104

Exceptional Persons, Inc. 1028 Headford, Box 690 Waterloo, Iowa 50701

\section{KANSAS}

Ft. Hays Kansas State College Hays, Kansas 67602

Kansas Univ. School of Medicine Dept. of Otolaryngology 39th \& Rainbow Kansas City, Kansas 66103

University of Kansas 4 Bailey Hall

Lawrence, Kansas 66045

Kansas State University Manhattan, Kansas 66045

Parsons State Hospital \& Training Center Parsons, Kansas 67357

Department of Logopedics Wichita State Univ. Wichita, Kansas 67219

\section{KENTUCKY}

University of Kentucky

Taylor Education Blidg.

Lexington, Kentucky 40503

Kentucky Society for Crippled Children $233 \mathrm{E}$. Broadway

Louisville, Kentucky 40202

Louisville General Hospital Louisville, Kentucky 40202

\section{LOUISIANA}

Baton Rouge Speech \& Hearing Foundation 574. W. Roosevelt Street

Baton Rouge, Louisiana 70802

Speech \& Hearing Clinic Music \& Dramatic Arts Building Louisiana State Univ. Baton Rouge, Louisiana 70803

Univ. of SW Louisiana Box 80, University Station Lafayette, Louisiana 70501

Crippled Children's Hospital 200 Henry Clay Avenue New Orleans, Louisiana 70118

Department of Otorhinolaryngology LSU School of Medicine 1542 Tulane Avenue New Orleans, Louisiana 70112
New Orleans Speech and Hearing Center 1636 Toledano

New Orleans, Louisiana 70115

Tulane Speech \& Hearing Center

Tulane Medical School

1430 Tulane Avenue

New Orleans, Louisiana 70112

Louisiana Polytechnic Institute Ruston, Louisiana 71270

MAINE

Bangor Regional Speech and Hearing Center 142 Pine Street

Bangor, Maine 04401

Northeast Hearing \& Speech Center, Inc. 690 Congress Street

Portland, Maine 04102

\section{MARYLAND}

Hearing \& Speech Agency of Metro. Baltimore, Inc. 938 North Charles Street

Baltimore, Maryland 21201

Hearing and Speech Center Johns Hopkins Hospital 601 N Broadway Baltimore, Maryland 21205

Univ. of Maryland, School of Medicine Greene \& Lombard Sts. Baltimore, Maryland 21201

University of Maryland College Park, Maryland 20742

\section{MASSACHUSETTS}

Boston Guild for the Hard-of-Hearing 283 Commonwealth Ave. Boston, Massachusetts 02115

Boston Univ. Medical Center 55 Stought on Street Boston, Massachusetts 02118

Harvard Univ. Medical School 243 Charles St.

Boston, Massachusetts 02114

Department of Otolaryngology University Hospital 750 Harrison Ave. Boston, Massachusetts 02118

Tufts Medical School 185 Harrison Avenue Boston, Massachusetts 02111

Winthrop Foundation \& Clinic for the Deaf Massachusetts Eye \& Ear Infirmary 243 Charles St.

Boston, Mass. 02114

Billerica Hearing \& Speech Society 117 Gray Street

East Billerica, Massachusetts 01821

The Franklin Co. Hearing \& Speech Center, Inc. 278 Main St., Room 407

Greenfield, Massachusetts 01301 
Springfield Hearing \& Speech Center, Inc.

77 Maple Street

Springfield, Massachusetts 01105

Worcester County Hearing

306 Main St.

Worcester, Mass. 01608

\section{MICHIGAN}

Audiology Div. of the Speech Clinic

Insitute for Human Adjustment

The University of Michigan

$1111 \mathrm{E}$. Catherine

Ann Arbor, Michigan 48104

Henry Ford Hospital 2799 W. Grand Blvd.

Detroit, Michigan 48202

Wayne State University

261 Mack Blvd.

Detroit, Michigan 48201

Detroit Hearing and Speech

1401 Ash Street

Detroit, Michigan 48208

Department of Audiology \& Speech Sciences Michigan State University

East Lansing, Michigan 48823

Lansing Society for Better Hearing 6160 Park Lake Road

East Lansing, Michigan 48823

Michigan Association for Better Hearing 724 Abbott Road

East Lansing, Michigan 48823

Flint Hearing Society

2522 Landon

Flint, Michigan 48504

Hearing and Speech Center of Grand Rapids 920 Cherry Street, S.E.

Grand Rapids, Michigan 49507

Jackson Society for Better Hearing

141 Baits Street

Jackson, Michigan 49262

Constance Brown Hearing \& Speech Center 301 West Cedar Street

Kalamazoo, Michigan 49006

Kalamazoo Society for Better Hearing 301 West Cedar Street

Kalamazoo, Michigan 49006

Speech and Hearing Clinic

Western Michigan University

Kalamazoo, Michigan 49001

Hearing \& Speech Department

Ingham Co. Rehabilitation Medical Center

Lansing, Michigan 48910

Western Michigan Society for Better Hearing 313 South James Street

Ludington, Michigan 49431

Midland Society for Better Hearing

1605 State St.

Midland, Michigan 48640
Speech and Hearing Clinic

Central Michigan University

Mount Pleasant, Michigan 48858

Muskegon Society for Better Hearing

425 Lyman Building

Muskegon, Michigan 49441

Owosso Society for Better Hearing

531 Pine Street

Owosso, Michigan 48867

Northern Michigan Hearing Society

Burns Clinic

Petoskey, Michigan 49770

Grand Traverse Association for Better Hearing 201 East 10th

Traverse City, Michigan 49684

\section{MINNESOTA}

University of Minnesota

Speech and Hearing Evaluation Center

Duluth, Minnesota 55800

Minneapolis Hearing Society

2100 Stevens Avenue

Minneapolis, Minnesota 55404

University of Minnesota

Speech and Hearing Evaluation Center

Minneapolis, Minnesota 55400

Mayo Clinic

Audiological Section

Rochester, Minnesota 55901

Otolaryngology Clinic

444 Lowry Medical Arts Building

350 St. Peter Street

St. Paul, Minnesota 55102

St. Paul Hearing Society

496 Endicott-on-Robert Building

St. Paul, Minnesota 55114

\section{MISSISSIPPI}

Mississippi State College for Women

Columbus, Mississippi 39701

Speech and Hearing Clinic

University of Southern Mississippi

Hattiesburg, Mississippi 39401

\section{MISSOURI}

Speech \& Hearing Clinic

Southeast Missouri State College

Cape Girardeau, Missouri 63701

Speech and Hearing Clinic

University of Missouri

Columbia, Missouri 65201

Children's Mercy Hospital

1710 Independence

Kansas City, Missouri 64106

Greater Kansas City Hearing and Speech Center

General Hospital

24th and Cherry Streets

Kansas City, Missouri 64108 
Speech \& Hearing Clinic

N. E. Missouri State College

Kirksville, Missouri 63501

Northwest Missouri State College Maryville, Missouri 64468

Central Institute for the Deaf Attn: Hearing Clinic 818 S. Euclid

St. Louis, Missouri 63110

Jewish Hospital of St. Louis 216 S. Kingshighway St. Louis, Missouri 63110

St. Louis Hearing and Speech Center 3600 North Grand Ave. St. Louis, Missouri 63107

St. Louis University

15 N. Grand

St. Louis, Missouri 63103

Speech \& Hearing Clinic Central Missouri State College Warrensburg, Missouri 64093

\section{MONTANA}

Montana State College Bozeman, Montana 59715

Montana Easter Seal Rehabilitation Center 4400 Central Ave.

Great Falls, Montana 59401

Montana State University Missoula, Montana 59801

\section{NEBRASKA}

Kearney State College Kearney, Nebraska 68847

Speech and Hearing Clinic Univ. of Nebraska 12 th \& R Streets Lincoln, Nebraska 68508

Creighton University Medical Dispensary 2305 S. 10th St.

Omaha, Nebraska 68108

Nebraska Psychiatric Institute 602 S. 44th Ave.

Omaha, Nebraska 68115

University of Nebraska Medical School 42nd \& Emilie Avenue Omaha, Nebraska 68105

\section{NEW HAMPSHIRE}

Crotched Mountain School for the Deaf Greenfield, New Hampshire 03047

\section{NEW JERSEY}

Newark Hearing Society 91 Beech Street

Arlington, New Jersey 07032

Hunterdon Medical Center Flenington, New Jersey 08822
Hearing \& Speceh Center of Iludson County 30-32 Journal Square

Jersey City, New Jersey 07306

St. Barnabas Medical Center

Old Short Hills Rd.

Livingston, New Jersey 07039

Mountainside Hospital

Montclair, New Jersey 07042

Barkhorn Memorial Hospital

77 Central Avenue

Newark, New Jersey 07102

State Teachers College

187 Broadway

Newark, New Jersey 07104

North Jersey Hearing and Speech Center 152 Market Street

Paterson, New Jersey 07505

Plainfield Hearing Society P. O. Box 388

Plainfield, New Jersey 07060

Newark State College

Morris Avenue

Union, New Jersey 07083

Montclair State College Upper Montclair, New Jersey 07043

Marie H. Katzenbach School for the Deat Sullivan Way

West Trenton, New Jersey 08625

NEW MEXICO

Alluquerque Hearing Society 2000 San Mateo, N.E. Albuquerque, New Mexico 87110

Lovelace Clinic 4800 Gibson Blvd., S.E. Albuquerque, New Mexico 87108

The Rehabilitation Center 1023 Stanford Dr., N.E. Albuquerque, New Mexico 87106

University of New Mexico Central Ave., N.E.

Albuquerque, New Mexico 87106

New Mexico School for Deaf 1060 Cerrillos Road Santa Fe, New Mexico 87501

NEW YORK

Communication Disorder Center Albany Medical Center 43 New Scotland Avenue Albany, New York 12208

Northeastern N.Y. Speech Center $652 \mathrm{~W}$ ashington Ave.

Albany, New York 12203

Rehabilitation Services, Inc. 204 Court St.

Binghamton, New York 13901 
A postolate for the Deaf and Hard of Hearing

191 Joralemon Street

Brooklyn, New York 11201

Brooklyn College

Bedford Ave. \& Ave. H.

Brooklyn, New York 11210

Hard of Hearing Clinic

Jewish Hospital of Brooklyn

555 Prospect Place

Brooklyn, New York 11238

Jewish Chronic Disease Hospital 86 E. 49 th St.

Brooklyn, New York 11203

Long Island University

DeKalb \& Flatbush Ave.

Brooklyn, New York 11201

State University of New York

Kings County Hospital

450 Clarkson Ave.

Brooklyn, New York 11203

Buffalo Hearing and Speech Center

325 Summer St.

Buffalo, New York 14222

Children's Hospital of Buffalo

936 Delaware Ave.

Buffalo, New York 14209

State University of New York at Buffalo 3435 Main St.

Buffalo, New York 14214

Meadowbrook Hospital

Hempstead Trnpk

East Meadow, Long Island, New York 11552

Queens Speech \& Hearing Center

Queens College of CUNY

Flushing, New York 11367

The Association for the Pre-School Deaf 43-45 Union Street

Flushing, New York 11355

C. W. Post College

Long Island,

Greenvale, New York 11548

Long Island Hearing and Speech Society 430 Lakeville Road

New Hyde Park, New York 11040

State University College of Education

New Paltz, New York 12561

Department of Hearing \& Speech

New York Eye and Ear Infirmary

Second Ave. Corner 13th St.

New York, New York 10003

Department of Otolaryngology

New York Hospital

Cornell Medical Center

525 E. 68th Street

New York, New York 10021

Harlem Eye and Ear Hospital 2099 Lexington Avenue

New York, New York 10035
Hearing \& Speech Center

Bellevue Hospital Center

Out-Patient Dept. 7th Floor

26th St. \& First Ave.

New York, New York 10016

Hearing and Speech Clinic

Manhattan Eye, Ear, \& Throat Hospital

210 E. 64th Street

New York, New York 10021

Hearing and Speech Center

University Hospital

New York University Medical Center

566 First Avenue

New York, New York 10016

Hospital for Special Surgery

535 E. 70th St.

New York, New York 10021

Hunter College

695 Park Ave.

New York, New York 10021

Institute of Physical Medicine and Rehabilitation 400 E. 34th St.

New York, New York 10016

Junior High School, No. 47-M 225 E. $23 \mathrm{St}$.

New York, New York 10010

Lenox Hill Hospital

210 E. 77 St.

New York, New York 10021

Lexington School for Deaf

904 Lexington Ave.

New York, New York 10021

New York City Hospital

Welfare Island Dispensary

80th St. \& East End Ave.

New York, New York 10028

New York League for the Hard of Hearing, Inc. 71 West 23rd Street

New York, New York 10010

New York University School of Education Press 32

New York, New York 10003

Section of Audiology and Phonology

Columbia Presbyterian Hospital

622 W. 168th St.

New York, New York 10032

Phelp`s Memorial Hospital

North Tarrytown, New York 10593

St. Charles Hospital

200 Belle Terre Rd.

Port Jefferson, New York 11777

St. Francis Hospital

North Road

Poughkeepsie, New York 12601

Genesee Hospital 224 Alexander

Rochester, New York 14607

Hearing and Speech Center of Rochester, Inc. 907 Culver Road

Rochester, New York 14609 
University of Rochester Medical School 260 Crittenden Blvd.

Rochester, New York 14620

Sunnyriew Rehabilitation Center 1270 Belmont Ave.

Schenectady, New York 12308

Syracuse University Hearing Center 805 South Crouse

Syracuse, New lork 13201

Children's Hospital \& Rehabilitation Center Hearing \& Speech Center

1675 Bennett St.

Utica, New York 13502

Goldwater Memorial Hospital

Welfare Island, New York 10017

\section{NORTH CAROLINA}

Speech \& Hearing Center

Asheville Orthopedic Hospital, Inc.

Asherille, North Carolina 28803

Hearing and Speech Center

N. C. Memorial Hospital

Univ. of North Carolina

Chapel Hill, North Carolina 27515

Speech \& Hearing Department

Charlotte Rehabilitation Hospital

1610 Brunswick Ave.

Charlotte, North Carolina 28203

Audiology Section

Speech and Hearing Center

Duke University Medical Center

Durham, North Carolina 27706

Speech and Hearing Center

Eastern Carolina University

Greenville, North Carolina 27834

Hearing \& Speech Center North Carolina Baptist Hospital

Winston-Salem, North Carolina 27103

Speech and Hearing Center

Bowman-Gray School of Medicine

Baptist Memorial Hospital

Winston-Salem, North Carolina 27104

\section{NORTH DAKOTA}

University of North Dakota

University Station

Grand Forks, North Dakota 58202

Speech and Hearing Clinic

Minot State College

Minot, North Dakota 58701

\section{OHIO}

Rehahilitation Center of Summit County, Inc. 326 Locust Street

Akron, Ohio 44302

Speech and Hearing Clinic

School of Hearing and Speech Sciences

S. College Street

Athens, Ohio 45701

Bowling Green Speech \& Hearing Clinic Bowling Green State University Bowling Green, Ohio 43402
Goodwill Industries and Rehabilitation Clinic

713 East Tuscarawas Street

Canton, Ohio 44707

Cincinnati League for the Hard of Hearing

616 Walnut Street

Cincinnati, Ohio 45202

Cincinnati Speech \& Hearing Center

3006 Vernon Place

Cincinnati, Ohio 45219

Cleveland Clinic

2020 E. 93rd Street

Cleveland, Ohio 44106

Cleveland Hearing and Speech Center, Inc.

11206 Euclid Avenue

Cleveland, Ohio 44106

Western Reserve University School of Medicine 11206 Euclid

Cleveland, Ohio 44106

Hearing \& Speech Center of Columhus \& Central Ohio

The Children's Hospital

17th Street at Livingston Park

Columbus, Ohio 43205

Speech and Hearing Clinic

Ohio State University

154 North Oval Drive

Columbus, Ohio 43210

Hearing and Speech Center of Dayton \& Montgomery County 1735 Chapel Street

Dayton, Ohio 45404

Delaware City-County Speech \& Hearing Center 153 West Lincoln

Delaware, Ohio 43015

Ohio Wesleyan University

Delaware, Ohio 43015

Speech and Hearing Clinic

Kent State University

Kent, Ohio 44240

Richland Hearing \& Speech Center 248 Blymyer Ávenue

Mansfield, Ohio 44903

Marietta College

Marietta, Ohio 45750

Department of Speecl

Miami University

Oxford, Ohio 45056

Scioto Speech and Hearing Clinic

180527 th Street

Portsmouth, Ohio 45662

Clark County Hearing \& Speech Center 1309 West First St.

Springfield, Ohio 45504

Department of Speech \& Hearing Therapy Betty Jane Memorial Rehabilitation Center 65 St. Francis Avenue

Tiffin, Ohio 44883

Toledo Hearing and Speech Center 2313 Ashland Avenue

Toledo, Ohio 43620 
Trumbull County Hearing Society

197 West Market

Warren, Ohio 44481

Youngstown Hearing \& Speech Center 69 1llinois Avenue

Youngstown, Ohio 44505

Muskingum Valley Hearing \& Speech Center 569 Brookover Avenue

Zanesville, Ohio 43701

\section{OKLAHOMA}

Speech and Hearing Clinic

Oklahoma College of Liberal Arts

7th at Colorado Avenue

Chickasha, Oklahoma 73019

Community Speech and Hearing Center Box 2262, University Station

Enid, Oklahoma 73701

University of Oklahoma

Norman, Oklahoma 73069

University of Oklahoma

Speech and Hearing Center

825 N. E. 14th Street

Oklahoma City, Oklahoma 73104

Oklahoma City Hearing Society

4016 N.W. 19th Street

Oklahoma City, Oklahoma 73107

Northeastern State College

Tahlequah, Oklahoma 74464

Speech and Hearing Clinic

University of Tulsa

600 S. College Avenue

Tulsa, Oklahoma 74104

\section{OREGON}

Southern Oregon College

Ashland, Oregon 97520

Eugene Speech and Hearing Center 1202 Almaden Street

Eugene, Oregon 97402

Eastern Oregon College of Education La Grande, Oregon 97850

Oregon College of Education Speech \& Hearing Center Monmouth, Oregon 97361

Kresge Hearing Research Laboratory Department of Otolaryngology Universty of Oregon Medical School 3181 SW Sam Jackson

Portland, Oregon 97201

\section{PENNSYLVANIA}

Lehigh Valley Society for Crippled Children Hearing and Speech Center

Muhlenberg Medical Center

Schoenersville Road

Bethlehem, Pennsylvania 18017

Bloomsburgh State College

Center for Disorders of Communication

Bloomsburg, Pennsylvania 17815
California State College

California, Pennsylvania 15419

Clarion State College

Clarion, Pennsylvania 16214

The Geisinger Medical Center Speech and Hearing Center

Danville, Pennsylvania 17821

Harrisburg Polyclinic Hospital

Third \& Polyclinic Street

Harrisburg, Pennsylvania 17105

Indiana University of Pennsylvania Indiana, Pennsylvania 15701

The Hearing Conservation Center of Lancaster County 630 Janet Avenue

Lancaster, Pennsylvania 17601

Hearing Conservation Center of Lancaster County, Inc.

24 N. Lime Street

Lancaster, Pennsylvania 17602

Hahnemann Medical College and Hospital 230 North Broad Street

Philadelphia, Pennsylvania 19102

Jefferson Medical College

1015 Walnut Street

Philadelphia, Pennsylvania 19082

Pennsylvania School for Deaf 7500 Germantown Avenue Philadelphia, Pennsylvania 19119

Philadelphia General Hospital 34 Street and Curie Avenue Philadelphia, Pennsylvania 19104

Philadelphia Hearing Society 2019 Spruce Street Philadelphia, Pennsylvania 19163

St. Christopher's Hospital for Children 2603 N. Fifth Street

Philadelphia, Pennsylvania 19133

Section of Audiology

Department of Otorhinology

Temple University Health Sciences Center

3400 N. Broad St.

Philadelphia, Pennsylvania 19140

University of Pennsylvania

School of Medicine

34th \& Spruce Street

Philadelphia, Pennsylvania 19104

U. S. Naval Hospital

17 \& Pattison

Philadelphia, Pennsylvania 19145

Children's Hospital of Pittsburgh

125 De Soto Street

Pittsburgh, Pennsylvania 15213

Department of Audiology

Eye \& Ear Hospital

University of Pittsburgh Medical School

230 Lothrop St.

Pittsburgh, Penna. 15213

The De Paul Institute

Castlegate Avenue

Pittsburgh, Pennsylvania 15226 
Pittsburgh, Pennsylvania 15219

Mount Mercy College 3333 Fifth Avenue

Pittsburgh, Pennsylvania 15213

Pittsburgh Hearing \& Speech Society Granite Building, 2nd Floor 313 Sixth Avenue

Pittsburgh, Pennsylvania 15222

Clinic for Rehabilitation of the Hard of Hearing Reading Hospital

6th \& Spruce

Reading, Pennsylvania 19603

Pennsylvania State University Speech and Hearing Clinic Sparks Building University Park, Pennsylvania 16802

West Chester State College 620 . S. High Street West Chester, Pennsylvania 19380

The Reading Hospital

West Reading, Pennsylvania, 19602

\section{RHODE ISLAND}

Hearing \& Speech Services of R. I., Inc. 333 Grotto Avenue

Providence, Rhode Island 02906

Rhode Island School for Deaf 520 Hope Street

Providence, Rhode Island 02906

\section{SOUTH CAROLINA}

Charleston Speech and Hearing Clinic 79 - 81 Alexander Street Charleston, South Carolina 29403

Medical College of South Carolina 80 Barre Street Charleston, South Carolina 29401

MCSC Hearing \& Speech Facility Medical College of South Carolina 55 Doughty Street

Charleston, South Carolina 29401

Hearing and Speech Center 1845 Assembly Street Columbia, South Carolina 29201

Florence Speech and Hearing Center Rt. 2, Darlington Highway Florence, South Carolina 29501

United Speech and Hearing Services of Greenville County 15 West Faris Road Greenville, South Carolina 29605

Speech and Hearing Clinic South Carolina State College Orangeburg, South Carolina 29115

Spartanburg Speech and Hearing Clinic 130 West Hampton Avenue Spartanburg, South Carolina 29301

South Carolina School for Deaf Spartanburg, South Carolina 29302
South Dakota School for Deaf

1800 E. 10th Street

Sioux Falls, South Dakota 57103

University of South Dakota

Vermillion, South Dakota 57609

\section{TENNESSEE}

Bristol Memorial Hospital

Bristol, Tennessee 37620

University of Chattanooga 529 Oak Street

Chattanooga, Tennessee 37403

West Tennessee Speech and Hearing Center 765 W. Forest Street

Jackson, Tennessee 38303

East Tennessee State University Johnson City, Tennessee 37601

University of Tennessee 1500 Yale Knoxville, Tennessee 37916

Memphis State University Speech and Hearing Center 807 Jefferson

Memphis, Tennessee 38105

The Bill Wilkerson Hearing and Speech Center 1114. 19th Avenue, South

Nashville, Tennessee 37212

Nashville League for the Hard of Hearing 1810 Edgehill Avenue

Nashville, Tennessee 37212

\section{TEXAS}

Amarillo Children's State Hospital Center 717 Crockett Street Amarillo, Texas 79102

Speech and Hearing Clinic Department of Speech The University of Texas at Austin Austin, Texas 78712

Speech and Hearing Clinic West Texas State College Canyon, Texas 79015

Speech and Hearing Clinic East Texas State College Commerce, Texas 75428

Callier Hearing and Speech Center 1966 Inwood Road Dallas, Texas 75235

Dalias Society for Crippled Children 2312 Oaklawn Avenue Dallas, Texas 75219

Speech and Hearing Clinic Southern Methodist University Hillcrest \& University Dallas, Texas 75222 
Texas Woman's University

Speech and Hearing Clinic

Box 3775

TWU Station

Denton, Texas 76204

Speech and Hearing Retardation Clinic

Texas Christian University

Fort Worth, Texas 76129

Hearing \& Speech Clinic

The University of Texas

Medical Branch

Galveston, Texas 77550

Houston Speech and Hearing Center

Texas Medical Center

1348 Moursund Avenue

Houston, Texas 77025

West Texas Hearing Clinic

Texas Technological College

Lubbock, Texas 79406

Sunnyside Speech and Hearing Clinic 3049 - 36 Street

Port Arthur, Texas 77604

Bexar County Hearing Society

406 West Market Street

San Antonio, Texas 78205

Scott and White Clinic

2401 South 3lst St.

Temple, Texas 76501

\section{UTAH}

Utah State University

Logan, Utah 84321

Department of Surgery

Division of Otolaryngology

Otoneurology and Audiology

College of Medicine

University of Utah

Salt Lake City, Utah 84112

Ear Nose and Throat Center of Salt Lake City 22 South Ninth East

Salt Lake City, Utah 84102

Primary Children's Hospital

320 12th Ave.

Salt Lake City, Utah 84103

University of Utah

Cooperative Research

207 Park Building

Salt Lake City, Utah 84112

\section{VERMONT}

Center for Disorders of Communication DeGoesbriand Memorial Hospital

Burlington, Vermont 05401

Vermont Association for the Crippled, Inc. 88 Park Street

Rutland, Vermont 05701

\section{VIRGINIA}

Speech and Hearing Center

109 New Cabell Hall

University of Virginia

Charlottesville, Virginia 22903
Madison College

Harrisonburg, Virginia 22802

Blue Ridge Speech \& Hearing Center

P. O. Box 290

Leesburg, Virginia 22075

Hampton Roads Speech \& Hearing Center, Inc. 9963 Warwick Blvd.

Newport News, Virginia 23601

Old Dominion College

Bluestone Ave. \& 48th St.

Norfolk, Virginia 23508

Department of Audiology

Box 157

Medical College of Virginia

1109 E. Clay Street

Richmond, Virginia 23219

Gill Eye and Ear Foundation

711 South Jefferson St.

Roanoke, Virginia 24011

Roanoke Valley Speech \& Hearing Clinic

2201 Carolina Ave., S.W.

Roanoke, Virginia 24014

Speech \& Hearing Clinic of Franklin Co. Rocky Mount, Virginia 24151

\section{WASHINGTON}

Speech Department

Walla Walla College

College Place, Washington 99324

Central Washington College Ellensburg, Washington 98926

Speech \& Hearing Clinic

Washington State University

Pullman, Washington 99163

Washington State University Library Road

Pullman, Washington 99163

Seattle Hearing \& Speech Center, Inc.

18th and East Madison

Seattle, Washington 98122

Speech and Hearing Clinic

University of Washington

1320 N.E. Campus Parkway

Seattle, Washington 98105

Inland Speech and Hearing Center

424 Paulsen Building

Spokane, Washington 99210 .

Spokane Hearing Society

East $618 \cdot 21$ st Ave.

Spokane, Washington 99203

WEST VIRGINLA

Kanawha Speech and Hearing Center

Memorial Hospital

3200 Noyes Ave., S. E.

Charleston, West Virginia 25304

Marshall College

Box 2

Huntington, West Virginia 25701 


\section{WISCONSIN}

Wisconsin State University Speech and Hearing Clinic Eau Claire, Wisconsin 54701

Green Bay Curative Workshop 342 South Webster Avenue Green Bay, Wisconsin 54301

Gunderson Clinic, Ltd. Department of Audiology La Crosse, Wisconsin 54601

Speech and Hearing Rehabilitation Center University of Wisconsin 905 University Ave.

Madison, Wisconsin 53706

University Hospital Otolaryngology Clinic 1300 University Ave. Madison, Wisconsin 53706

University of Wisconsin Medical Center 1300 University Ave.

Madison, Wisconsin 53706

Marshfield Clinic Department of Otolaryngology Marchfield, Wisconsin 54449

Marquette University Speech Clinic and Hearing Lab. $615 \mathrm{~N}$ 1lth

Milwaukee, Wisconsin 53233

Milwaukee County General Hospital Department of Audiology-ENT Outpatient 8700 West Wisconsin Avenue Milwaukee, Wisconsin 53226

Milwaukee Hearing Society 744 N. 4th Street

Milwaukee, Wisconsin 53203

St. Luke's Hospital Department of Audiology 2900 West Oklahoma Avenue Milwaukee, Wisconsin 53215

University of Wisconsin-Milwaukee Department of Communication Hearing Evaluation Center Merrill Hall-3203 Downer Avenue Milwaukee, Wisconsin 53201

Oshkosh Public Schools Hearing Clinic 1109 East Melvin Avenue Oshkosh, Wisconsin 54901

University of Wisconsin Speech Department-Speech and Hearing Clinic Oshkosh, Wisconsin 54901

Dominican College 5915 Erie St.

Racine, Wisconsin 53402

Sheboygan Clinic Department of Audiology and Speech Sheboygan, Wisconsin 53081

Speech and Hearing Clinic Stevens Point, Wisconsin 54481

University of Wyoming

Box 3281, University Station

Laramie, Wyoming 82071

VETERANS ADMINISTRATION FACILITIES*

VA Hospital

Tucson, Arizona 85713

VA Hospital

300 E. Roosevelt Road

Little Rock, Arkansas 72206

VA Outpatient Clinic

1031 S. Broadway

Los Angeles, California 90015

VA Hospital

42nd Ave. \& Clement St.

San Francisco, California 94121

VA Hospital

1055 Clermont Street

Denver, Colorado 80220

State Veterans Hospital

Rocky Hill, Connecticut 06067

VA Hospital

50 Irving St., N.W.

Washington, DC 20422

VA Hospital

Coral Gables, Florida 33134

VA Regional Office

P. O. Box 1437

St. Petersburg, Florida 33731

VA Hospital Clairmont Road, NE

P. O. Box 29457

Atlanta, Georgia 30329

VA West Side Hospital 820 South Damen Ave. Chicago, Illinois 60612

VA Hospital Iowa City, Iowa 52241

VA Regional Office 1405 West Broadway Louisville, Kentucky 40201

VA Hospital 1601 Perdido Street New Orleans, Louisiana 70140

VA Outpatient Clinic 17 Court Street Boston, Massachusetts 02108

VA Hospital 2215 Fuller Road Ann Arbor, Michigan 48105

VA Center

Fort Snelling

St. Paul, Minnesota 55111

-Underline designates new state. 
VA Hospital

4801 Linwood Blvd.

Kansas City, Missouri 64128

VA Regional Office

20 Washington Place

Newark, New Jersey 07102

VA Regional Office

252 Seventh Avenue

New York, New York 10001

VA Hospital

Irving Ave. \& University Pl.

Syracuse, New York 13210

VA Hospital

Fulton St. \& Erwin Rd.

Durham, North Carolina 27705

VA Hospital

10701 East Blyd.

Cleveland, Ohio 44106

VA Hospital

921 Northeast 13th Street

Oklahoma City, Oklahoma 73104
Portland Center for Hearing \& Speech 3515 S.W. Veterans Hospital Road Portland, Oregon 97201

VA Outpatient Clinic 128 North Broad St.

Philadelphia, Pennsylvania 19102

VA Hospital

University Drive

Pittsburgh, Pennsylvania 15240

VA Center 520 Ponce de Leon Ave. San Juan, Puerto Rico 00901

VA Hospital 4500 S. Lancaster Road

Dallas, Texas 75216

VA Hospital 2002 Holcombe Blvd. Houston, Texas 77031

VA Hospital 4435 Beacon Ave, South Seattle, Washington, 98108 
Latest developments in the subject area of this publication, as well as in other areas where the National Bureau of Standards is active, are reported in the NBS Technical News Bulletin. See following page. 


\section{HOW TO KEEP ABREAST OF NBS ACTIVITIES}

Your purchase of this publication indicates an interest in the research, development, technology, or service activities of the National Bureau of Standards.

The best source of current awareness in your specific area, as well as in other NBS programs of possible interest, is the TECHNICAL NEWS BULLETIN, a monthly magazine designed for engineers, chemists, physicists, research and product development managers, librarians, and company executives.

If you do not now receive the TECHNICAL NEWS BULLETIN and would like to subscribe, and/or to review some recent issues, please fill out and return the form below.

Mail to: Office of Technical Information and Publications National Bureau of Standards

Washington, D. C. 20234

Name

Affiliation

Address

City State Zip

Please send complimentary past issues of the Technical News Bulletin.

Please enter my 1-yr subscription. Enclosed is my check or money order for $\$ 3.00$ (additional $\$ 1.00$ for foreign mailing). check is made payable to: SUPERINTENDENT OF DOCUMENTS. Mono-117 



\section{PERIODICALS}

JOURNAL OF RESEARCH reports National Bureau of Standards research and development in physics, mathematics, chemistry, and engineering. Comprehensive scientific papers give complete details of the work, including laboratory data, experimental procedures, and theoretical and mathematical analyses. Illustrated with photographs, drawings, and charts.

Published in three sections, available separately:

\section{Physics and Chemistry}

Papers of interest primarily to scientists working in these fields. This section covers a broad range of physical and chemical research, with major emphasis on standards of physical measurement, fundamental constants, and properties of matter. Issued six times a year. Annual subscription: Domestic, $\$ 9.50$; foreign, $\$ 11.75^{*}$.

\section{Mathematical Sciences}

Studies and compilations designed mainly for the mathematician and theoretical physicist. Topics in mathematical statistics, theory of experiment design, numerical analysis, theoretical physics and chemistry, logical design and programming of computers and computer systems. Short numerical tables. Issued quarterly. Annual subscription: Domestic, $\$ 5.00$; foreign, $\$ 6.25 *$.

\section{Engineering and Instrumentation}

Reporting results of interest chiefly to the engineer and the applied scientist. This section includes many of the new developments in instrumentation resulting from the Bureau's work in physical measurement, data processing, and development of test methods. It will also cover some of the work in acoustics, applied mechanics, building research, and cryogenic engineering. Issued quarterly. Annual subscription: Domestic, $\$ 5.00$; foreign, $\$ 6.25 *$.

\section{TECHNICAL NEWS BULLETIN}

The best single source of information concerning the Bureau's research, developmental, cooperative and publication activities, this monthly publication is designed for the industry-oriented individual whose daily work involves intimate contact with science and technology-for engineers, chemists, physicists, research managers, product-development managers, and company executives. Annual subscription: Domestic, $\$ 3.00$; foreign, $\$ 4.00^{*}$.

- Difference in price is due to extra cost of foreign mailing.
NONPERIODICALS

Applied Mathematics Series. Mathematical tables, manuals, and studies.

Building Science Series. Research results, test methods, and performance criteria of building materials, components, systems, and structures.

Handbooks. Recommended codes of engineering and industrial practice (including safety codes) developed in cooperation with interested industries, professional organizations, and regulatory bodies.

Special Publications. Proceedings of NBS conferences, bibliographies, annual reports, wall charts, pamphlets, etc.

Monographs. Major contributions to the technical literature on various subjects related to the Bureau's scientific and technical activities.

National Standard Reference Data Series. NSRDS provides quantitative data on the physical and chemical properties of materials, compiled from the world's literature and critically evaluated.

Product Standards. Provide requirements for sizes, types, quality and methods for testing various industrial products. These standards are developed cooperatively with interested Government and industry groups and provide the basis for common understanding of product characteristics for both buyers and sellers. Their use is voluntary.

Technical Notes. This series consists of communications and reports (covering both other agency and NBS-sponsored work) of limited or transitory interest.

Federal Information Processing Standards Publications. This series is the official publication within the Federal Government for information on standards adopted and promulgated under the Public Law 89-306, and Bureau of the Budget Circular A-86 entitled, Standardization of Data Elements and Codes in Data Systems.

Order NBS publications from:

Superintendent of Documents

Government Printing Office

Washington, D.C. 20402 


\title{
U.S. DEPARTMENT OF COMMERCE
}

WASHINGTON, D.C. 20230

\author{
OFFICIAL BUSINESS
}

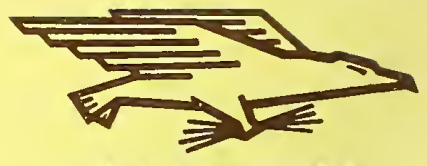

POSTAGE AND FEES PAID

U.8. DEPARTMENT OF COMMERCE

PENALTY FOR PRIVATE USE, $\$ 300$ 